\title{
Correction to: Gear selectivity of functional traits in coral reef fisheries in Brazil
}

\author{
Felipe Carvalho $^{1}$ (I) Leandro Castello $^{1} \cdot$ Beatrice Ferreira $^{2} \cdot$ Gavin $_{\text {McDonald }}{ }^{3}$. \\ Michael Power ${ }^{4}$
}

Published online: 29 December 2021

(C) Springer-Verlag GmbH Germany, part of Springer Nature 2021

\section{Correction to: Coral Reefs (2021) 40:1915-1929 \\ https://doi.org/10.1007/s00338-021-02192-w}

Author discovered last two figures that were uploaded during proofing have minor inconsistencies. Figure \#3 was missing the sample size boxes within each plot, whereas figure\#4 was missing the axis labels.

Original article has been updated.

Publisher's Note Springer Nature remains neutral with regard to jurisdictional claims in published maps and institutional affiliations.

The original article can be found online at https://

doi.org/10.1007/s00338-021-02192-w.

Felipe Carvalho

fmc@vt.edu

1 Department of Fish and Wildlife Conservation, Virginia Polytechnic Institute and State University, Blacksburg, VA, USA

2 Department of Oceanography, Federal University of Pernambuco, Recife, Brazil

3 Marine Science Institute, University of California at Santa Barbara, Santa Barbara, CA, USA

4 Department of Biology, University of Waterloo, Waterloo, ON, Canada 